\title{
High-Resolution AEM and XAS Study of Ru, Pt and Ru-Pt Supported Nanocatalysts
}

\author{
V.P. Oleshko ${ }^{*}$, W.C. Ketchie ${ }^{* *}$, E.P. Maris ${ }^{* *}$, and R.J. Davis ${ }^{* *}$ \\ *Department of Materials Science \& Engineering, University of Virginia, Charlottesville, VA \\ 22904-4745 \\ ** Department of Chemical Engineering, University of Virginia, Charlottesville, VA 22904-4741
}

In order to find alternatives to fossil-based and petroleum-derived precursors for the production of chemicals and fuels, significant efforts are currently focused on biorenewable resources, such as carbohydrates [1-4], and on development of environmentally clean energy sources, such as direct ethanol fuel cells based on Pt-Ru/C electrocatalysts [5,6]. As a first step for the production of biofuels and other industrially important chemical products, a sugar such as glucose can be hydrogenated to form sorbitol. Sorbitol is used in the production of vitamin $\mathrm{C}$ and is a precursor for lower molecular weight oxygenated chemicals. Although supported noble metal catalysts are known to be effective in the hydrogenation of glucose to sorbitol, their stability and transformations under hydrogenation conditions is still an open question. The objective of this work is to use highresolution analytical electron microscopy (AEM) combined with X-ray absorption spectroscopy (XAS) to obtain nanoscale structural and analytical information on the supported $\mathrm{Ru}, \mathrm{Ru}-\mathrm{Pt}$ and $\mathrm{Pt}$ nanocatalysts active in the aqueous phase conversion of glucose to sorbitol and further hydrogenolysis of sorbitol.

$\mathrm{Ru}, \mathrm{Ru}-\mathrm{Pt}$ and $\mathrm{Pt}$ nanocatalysts (0.5-60 wt.\% transition metal) supported on $\mathrm{SiO}_{2}$ and carbon black were prepared as described elsewhere [7] Conventional BF-/DF-TEM, selected-area electron diffraction (SAED), phase-contrast high-resolution (HR) TEM and energy-dispersive X-ray spectroscopy (EDXS) of the samples were performed on a JEOL JEM-2010F field-emission AEM operating at $200 \mathrm{kV}$ with a high-tilt pole piece $\left(\mathrm{C}_{\mathrm{s}}=1.0 \mathrm{~mm}\right.$ and $0.23 \mathrm{~nm}$ resolution by points $)$ and utilizing an Oxford Pentafet ultrathin window EDX detector with resolution of $136 \mathrm{eV}(\mathrm{MnK} \alpha)$. XAS was done at the National Synchrotron Light Source (Brookhaven National Lab). In-situ XAS and ex-situ TEM observations of the catalysts before and after reaction indicated that Ru particles agglomerated on the $\mathrm{SiO}_{2}$ surface following exposure to liquid water at $373 \mathrm{~K}$ [7]. Aqueous-phase glucose appeared to have a stabilizing effect on the oxidized Ru particles of the as-prepared catalyst. TEM suggests that there was little growth of Ru particles during the standard hydrogenation reaction (Table 1). Ru particles migrated to regions of higher particle density but did not necessarily coalesce into larger particles. $\mathrm{Ru}$ agglomeration under aqueous conditions was related to $\mathrm{SiO}_{2}$ supports; during experiments conducted on carbon-supported catalysts, there was negligible agglomeration of $\mathrm{Ru}$ particles. $\mathrm{Ru} / \mathrm{SiO}_{2}$ and $\mathrm{Ru} / \mathrm{C}$ samples were characterized to determine their stability under sorbitol hydrogenolysis conditions. Extended X-ray absorption fine structure (EXAFS) analysis shows that both of the catalysts were highly dispersed following reduction with $\mathrm{H}_{2}$ at $473 \mathrm{~K}$. However, in-situ XAS of the $\mathrm{Ru} / \mathrm{SiO}_{2}$ and $\mathrm{Ru} / \mathrm{C}$ samples under 40 bar $\mathrm{H}_{2}$-saturated aqueous solution at $473 \mathrm{~K}$ resulted in extensive particle growth of the $\mathrm{Ru} / \mathrm{SiO}_{2}$ sample while the $\mathrm{Ru} / \mathrm{C}$ sample remained highly dispersed. HRTEM, SAED, EDXS and XAS were employed to investigate a series of supported $\mathrm{Ru}, \mathrm{Pt}$, Ru-Pt catalysts to be used for sorbitol hydrogenolysis. The preparation method resulted in average particles sizes for all catalysts of less than $4 \mathrm{~nm}$ (Table 1, FIGs 1a and 1b). EXAFS and Nanoprobe EDXS analyses of the monometallic and bimetallic catalysts using probe sizes varying from 2.4 to $0.5 \mathrm{~nm}$ down to one atomic column (FIG. 1c) proved that in the latter case 
hep $\mathrm{Ru}$ and fcc $\mathrm{Pt}$ were interacting to form rounded mixed composition nanoparticles with essentially unimodal size distributions (FIG. 1b) rather than segregated clusters on the support.

Table 1. Mean particle size and EXAFS fit results for $\mathrm{Ru} / \mathrm{SiO}_{2}, \mathrm{Ru} / \mathrm{C}$, bimetallic $\mathrm{Ru}-\mathrm{Pt} / \mathrm{C}$ and $\mathrm{Pt} / \mathrm{C}$ catalysts of the absorber-scatterer $1^{\text {st }}$ shell, samples analyzed in-situ under varying treatments. (A) 1.01 bar $\mathrm{H}_{2}(\mathrm{~g})$ at $298 \mathrm{~K}$, following reduction at $473 \mathrm{~K}$; (B) 40 bar $\mathrm{H}_{2}$ saturated water at $373 \mathrm{~K}$; and (C) $1.01 \mathrm{bar}_{2}(\mathrm{~g})$ at $79 \mathrm{~K}$, following reduction at $473 \mathrm{~K}$.

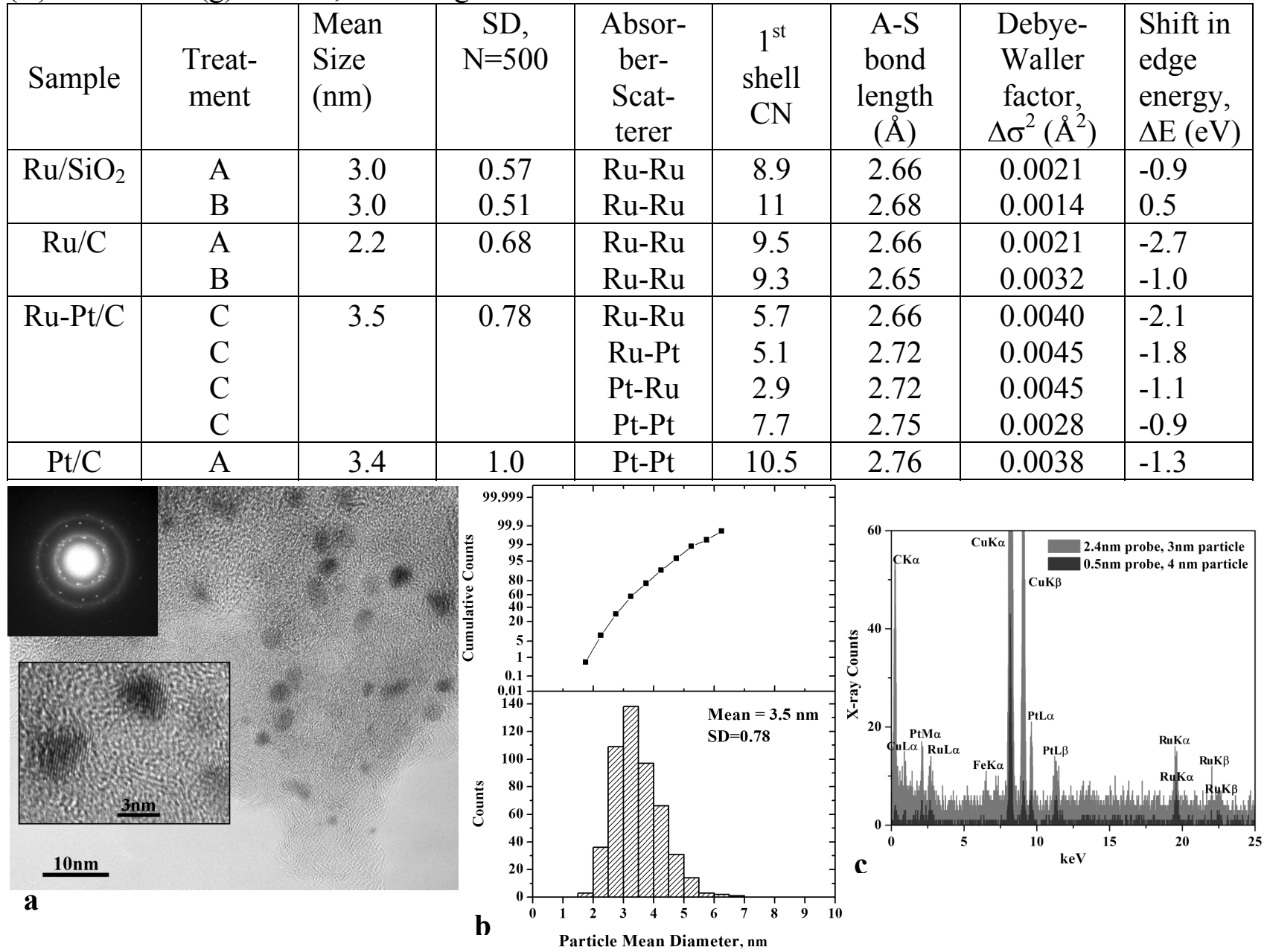

FIG. 1. (a) HRTEM and SAED (upper inset) of Ru-Pt bimetallic particles of 2-4 $\mathrm{nm}$ in size supported with a carbon black. Enlarged bottom inset shows $\{111\}$ fcc lattice fringes. (b) Cumulative (top) and differential (bottom) histograms on size distribution of Ru-Pt nanoparticles, 500 counts, mean diameter, $\mathrm{d}_{\text {mean }}=3.5 \mathrm{~nm}, \mathrm{SD}=0.78 \mathrm{~nm}, \mathrm{SE}=0.1 \mathrm{~nm}$ (c) EDX spectra of individual 3$4 \mathrm{~nm}$ diameter Ru-Pt nanoparticles acquired using 2.4 and $0.5 \mathrm{~nm}$ diameter electron probes, respectively, $60 \mathrm{~s}$ acquisition time, $15^{\circ}$ tilt, $10 \mathrm{eV} /$ channel dispersion, $\mathrm{x} 1 \mathrm{M}$ magnification.

References

[1] R.R. Davda et al. Appl. Catal. B: Environ. 56 (2005) 171. [2] R.D. Cortright et al. Appl. Catal. B: Environ. 39 (2002) 353. [3] N.Y. Chen et al. Chemtech, August (1986) 506. [4] F.W. Lichtenthaler, S. Mondel. Pure Appl. Chem. 69 (1997) 1853. [5] G.S. Chai et al., J. Phys. Chem. B 108 (2004) 7074. [6] Liu et al., J. Powder Sources 149 (2005) 1. [7] E.P. Maris et al. J. Phys. Chem. B (2006) submitted. [8] Authors acknowledge the support from the NSF, grant CTS-0313484 (WCK and EPM) and from the DOE, contract DE-FG02-01ER45918 (VPO). 